\title{
Adhesiveness of Cold Rolled Steels for Car Body Parts
}

\author{
Kleiner Marques Marra ${ }^{\mathrm{a}}$, Evandro de Azevedo Alvarenga ${ }^{\mathrm{a}}$, Vicente Tadeu Lopes Buono ${ }^{\mathrm{b}}$ * \\ ${ }^{a}$ Usiminas Research and Development Center, Rod. BR 381, 35160-900 Ipatinga - MG, Brazil \\ ${ }^{\mathrm{b}}$ Federal University of Minas Gerais, Department of Metallurgical and Materials Engineering, \\ Rua Espirito Santo, 35, 30160-030 Belo Horizonte - MG, Brazil
}

Received: January 4, 2007; Revised: June 23, 2007

\begin{abstract}
The aim of this work was to evaluate the adhesiveness of uncoated and zinc-electrogalvanized steel sheets used in the automotive industry. Three types of adhesives, one acrylic and two epoxy resins, were employed to join low carbon cold rolled steels, one uncoated and another electrogalvanized, both previously degreased or chemically pickled. Mechanical strength of the joints was evaluated by the T-peel and tensile strength tests. Steel grade, surface condition and heating below the cure temperatures did not influence the joints' mechanical strength. However, their shear strength decreased drastically as the test temperature increased. The exposure of the joints to an atmosphere with $90 \%$ relative humidity at $40{ }^{\circ} \mathrm{C}$ caused reduction of their shear strength. Epoxy adhesives showed higher mechanical strength, but exhibited higher degradation by humidity.
\end{abstract}

Keywords: low carbon steels, adhesives, degradation, epoxy resins, acrylic resins

\section{Introduction}

Adhesives are used to join parts of similar or dissimilar materials, being constituted by mixtures of substances with several functions. The main components of adhesives are macromolecular or polymeric substances. They can be applied to the adherent's surfaces in liquid, pasty or solid state, but in the final stage of the joining process the adhesives should have low viscosity in order to wet entirely the surfaces to be joined and to produce a good adhesiveness after curing.

In general, adhesion mechanisms can be grouped as follows ${ }^{1-3}$ : i) mechanical interlocking, in which the adhesive penetrates into micro-irregularities present on the adherents surfaces, contributing to a strong adhesion. A good wettability is an important requirement for this adhesion mechanism; ii) electronic adhesion, based on chemical bonding associated with the transference of electrons between the adhesive and the adherent to balance the Fermi energy levels. Electrostatic forces are responsible for this type of adhesion; and iii) physical adsorption, in which the adhesive and the adherent are joined by forces established on their interfaces, associated with appropriate intermolecular contact.

The use of adhesives to join steel and aluminum parts is growing continuously in the car and airplane industries. More recently, adhesive bonding has been applied to repair pipes in fluid transport systems ${ }^{4}$, and the possibility of its use in steel constructions has been demonstrated: adhesive connections showed higher strength and stiffness than bolted connections ${ }^{5}$. In the beginning of the last decade, adhesives were used in more than fifty different car parts, to join metallic materials, glasses, leather, plastic and others ${ }^{6}$. When structural adhesives are applied to join steel parts of the car body, the benefits are related to reducing the weight, increasing the rigidity, reducing vibration and noise and also closing gaps and holes. Also, particular attention is directed towards the finishing characteristics, since adhesive bonding of steel parts of car bodies reduces considerably the incidence of undesirable surface irregularities associated with welds, screws, nuts or rivets ${ }^{6,7}$. Besides that, it is well known that adhesive bonding is the preferred jointing method when fatigue of structures involving bonded parts is considered ${ }^{8}$.
The surface condition of adherents generally plays an important role in establishing a strong and durable bond. Adequate surface cleaning treatments of the adherent parts, before the application of adhesives, are thus of fundamental importance. Adhesively bonded steel parts are commonly degreased with chemical solvents, followed by pickling with hydrochloric or sulfuric acids. More recently, gritblasting has been shown to increase adhesion of steel joints 9

Despite the advantages promoting the use of adhesive bonding of metallic parts, important issues remain to be solved, because the mechanical properties of bonded joints are generally influenced by a number of factors, such as the type of adhesive employed, the nature and surface roughness of the metallic adherents, the wet angle and the test temperature ${ }^{1,2,7-11}$. Adhesive degradation due to exposure in atmospheres with high relative humidity and relatively high temperatures deserves special attention for the use of adhesive bonding in the automotive industry ${ }^{8-10}$. Under certain atmospheric conditions, chemical reactions can lead to loss of adhesion and decrease in the mechanical strength of the joints. Adhesive embrittlement and oxide formation at adherent/adhesive interfaces have been pointed out as the main causes of this loss of adhesion ${ }^{10}$.

In this work, the adhesiveness of uncoated and zinc-electrogalvanized steel sheets used in the automotive industry was evaluated, using three types of adhesives, one acrylic and two epoxy resins, of the type employed in car bodies. Loss of adhesive strength was evaluated by means of mechanical tests performed at different temperatures and in joints previously heat treated under usual and high humidity atmospheres. The aim was to identify the influence of the various parameters investigated on the mechanical properties of the most common adhesive steel joints used in the automobile industry.

\section{Experimental}

The adhesive called A1 in this work is a non-structural type and has an acrylic resin as the base substance. It is normally used to close gaps and holes in car bodies. Two other adhesives were also employed. 
They are structural adhesives, designated as E1 and E2, and have epoxy resins as the base component. Table 1 presents the informations about them given by the suppliers for the automobile industry.

The two adherents employed in this investigation are low-carbon cold-rolled steels used in car bodies. One of them, called here the "basic steel" - BS, is uncoated, and the other, referred to as the "electrogalvanized steel" - EGS, was electrogalvanized with zinc $\left(70 / 70 \mathrm{~g}^{-\mathrm{m}^{-2}}\right)$ in an industrial production line. Their chemical composition is basically the same and both materials were evaluated as $0.70 \mathrm{~mm}$ thick sheet specimens.

Due to the necessity of a good contact between adhesive and adherent to promote joints with suitable mechanical strength, the wet angle was measured after annealing the joints at $180{ }^{\circ} \mathrm{C}$ for $20 \mathrm{~min}$ utes. This condition corresponds to the curing recommendations stated in Table 1. Since the surface roughness is another important factor to produce a good mechanical strength, this property was evaluated by the use of a Mitutoyo roughness surface tester. In the case of BS steel specimens, the joints were prepared using two surface conditions: i) only degreasing with tetrachloroethylene; and ii) degreasing followed by pickling with hydrochloric acid (15\%). The EGS steel was only evaluated under the degreased condition. The adhesives were applied to the adherent surfaces with a spatula, covering completely the area to be joined with a fine layer of approximately $0.5 \mathrm{~mm}$ in thickness.

The mechanical strength of the joints was evaluated by two types of mechanical tests: the T-peel test (ASTM D 1876), in which tensile stress is applied to the adhesive/adherent interface, and the tensile strength test (ASTM D 1002), involving the induction of shear stresses on the interfaces. The mechanical tests were performed in an Instron test machine, at a cross head speed of $5 \mathrm{~mm} / \mathrm{min}$. The ratio between the rupture load and the joined area was taken as the mechanical strength of the joints tensile tested. The rupture load was the maximum value reached during the test. In the T-peel test, the results are expressed as the ratio of the average load by the width of the adhesion area. All results of mechanical strength reported here are the averages of three tests performed under identical conditions. Average standard deviations were smaller than $20 \%$ in all tests. Fracture surfaces were observed by scanning electron microscopy - SEM, in a Cambridge Stereoscan 360 microscope.

To verify the influence of temperature on the mechanical strength of the joints, tensile strength tests were realized at the following temperatures: $-20,0,25,50,90,130$ and $180^{\circ} \mathrm{C}$. Another evaluation, using the same type of test, was performed at room temperature, with joints previously heat treated at $50,90,130$ and $180^{\circ} \mathrm{C}$ for 30 minutes. In this case, the joints were tested to verify whether the adhesives are susceptible to heating embrittlement.

The sensitivity to humidity degradation was evaluated in joints of the BS steel (degreased and pickled) and of the EGS steel (degreased), previously exposed in a humid cabinet, at $40{ }^{\circ} \mathrm{C}$ and $90 \%$ of relative humidity. The temperature and relative humidity degree were chosen to simulate severe atmospheric conditions. During one year, within intervals of two months, specimens were taken out of the humid cabinet and submitted to the tensile strength test.

\section{Results and Discussion}

\subsection{Adherents surface roughness}

The surface roughness of the adherents, measured in the rolling direction, is shown in Figure 1. The electrogalvanized steel exhibits the highest roughness, associated with the presence of zinc crystals in the coating, giving rise to a more irregular surface. The BS steel in the degreased and pickled condition shows a rougher surface, as compared to the same material that was only degreased. This means that the pickling acid solution caused a strong chemical attack of the steel surface.

\subsection{Wet angles}

Table 2 shows that the adhesives, after curing at $180{ }^{\circ} \mathrm{C}$, exhibit wet angles varying from $30^{\circ}$ (adhesive E1, degreased BS steel) to

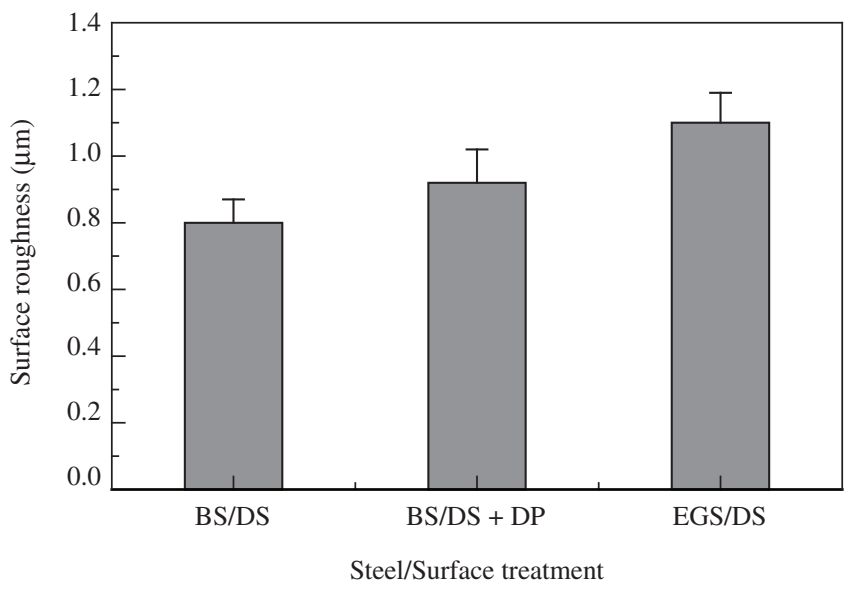

Figure 1. Longitudinal average roughness of the adherents.

Table 2. Wet angles of adhesives on the adherents after annealing at $180^{\circ} \mathrm{C}$.

\begin{tabular}{|c|c|c|c|}
\hline Adhesive & Adherent & Cleaning ${ }^{\mathrm{a}}$ & Wet angle $\left(^{\circ}\right)$ \\
\hline E1 & BS & DS & 30 \\
\hline E2 & BS & DS & 45 \\
\hline A1 & BS & DS & 70 \\
\hline E1 & BS & $\mathrm{DS}+\mathrm{DP}$ & 35 \\
\hline E2 & BS & $\mathrm{DS}+\mathrm{DP}$ & 45 \\
\hline A1 & $\mathrm{BS}$ & $\mathrm{DS}+\mathrm{DP}$ & 90 \\
\hline E1 & EGS & DS & 55 \\
\hline E2 & EGS & DS & 60 \\
\hline A1 & EGS & DS & 85 \\
\hline
\end{tabular}

${ }^{\mathrm{a}}$ Cleaning: DS = degreased with tetrachloroethylene, $\mathrm{DP}$ = pickled with $\mathrm{HCl}$ $15 \%$.

Table 1. Information about the adhesives given by the suppliers (flow time and density values at $25^{\circ} \mathrm{C}$ ).

\begin{tabular}{ccccl}
\hline Adhesive & Flow time $(\mathrm{s})$ & Density $\left(\mathrm{g} . \mathrm{cm}^{-3}\right)$ & Max. storage time at temperature & Curing conditions \\
\hline E1 & 420 & 1.45 & 8 months $/ 10^{\circ} \mathrm{C}$ or 6 months $/ 25^{\circ} \mathrm{C}$ & $170{ }^{\circ} \mathrm{C} / 20 \mathrm{~min}$ \\
E2 & 285 & 1.40 & 6 months $/ 10^{\circ} \mathrm{C}$ or 3 months $/ 25^{\circ} \mathrm{C}$ & $140{ }^{\circ} \mathrm{C} / 40 \mathrm{~min}$ or $180{ }^{\circ} \mathrm{C} / 13 \mathrm{~min}$ \\
A1 & 032 & 1.30 & 6 months $/ 10^{\circ} \mathrm{C}$ or 2 months $/ 25^{\circ} \mathrm{C}$ & $180{ }^{\circ} \mathrm{C} / 20 \mathrm{~min}$ \\
\hline
\end{tabular}

Flow times determined in viscosity tests. 
$90^{\circ}$ (adhesive A1, degreased and pickled BS steel). Considering that at room temperature all the adhesives presented a pasty consistency, and that the adhesive A1 had smaller density and viscosity than the others (Table 1), this means that the adhesive A1 became more viscous after heating at $180^{\circ} \mathrm{C}$, the curing temperature. In this condition, the wet angles decreased from A1 to E1, while adhesive E2 occupies an intermediate position. Resin E1 always presented the best wettability. Although, in general, the EGS steel showed higher values of wet angle than the BS steel after curing, the heat treatment turned adhesive E1 less viscous, while the behavior of adhesive A1 was the inverse, independently of the adherent. Table 2 also shows that the surface condition of the adherents influenced the wet angle. After degreasing and pickling, the BS steel showed a higher wet angle than the same material in the degreased condition. These differences can be explained by the surface tension established between the adhesive and the adherent, which increases as the surface roughness increases.

\subsection{Mechanical tests}

The average values of the results obtained in the T-peel and tensile strength tests are shown in Table 3. Although different adhesives produced different results, it can be observed that the metallic substrates did not significantly affect the mechanical strength of the joints. In the tensile strength tests, the acrylic adhesive joints A1 showed inferior strength as compared to the epoxy adhesive E1 and E2. However, in the T-peel tests, adhesive A1 and E2 practically show the same strength.

As usual in mechanical testing of adhesive bonded joints, two failure modes were observed in the fractured specimens observed by SEM: the adhesive mode, taking place at the interface between adhesive and adherent (Figure 2a), and the cohesive mode, which occurs in the adhesive bulk (Figure $2 \mathrm{~b})^{8}$. Table 3 shows that the cohesive failure occurred more frequently in the peeling test. In the tensile strength test, joints made with adhesive E1 showed higher susceptibility to interface failure than the other adhesives. The predominance of failures in the adhesive mode in the tensile strength tests indicates that the adhesion force, under shear loads, corresponds to the intrinsic mechanical strength of the interface. The lowest mechanical strength shown by adhesive A1 is related to the fact that it is not a structural adhesive, and thus has a reduced intrinsic strength.

\subsection{Variation of the shear strength with temperature}

The values of average shear strength obtained at different test temperatures are shown in Figure 3. The joints with the adhesive E1 maintained their mechanical strength up to $90{ }^{\circ} \mathrm{C}$. Above this temperature, there was an effective decrease in the shear strength. On the other hand, adhesive E2 exhibited this transition temperature around $50{ }^{\circ} \mathrm{C}$. It was also observed that the failures at higher temperatures occurred in the bulk of the adhesives. This behavior can be associ-

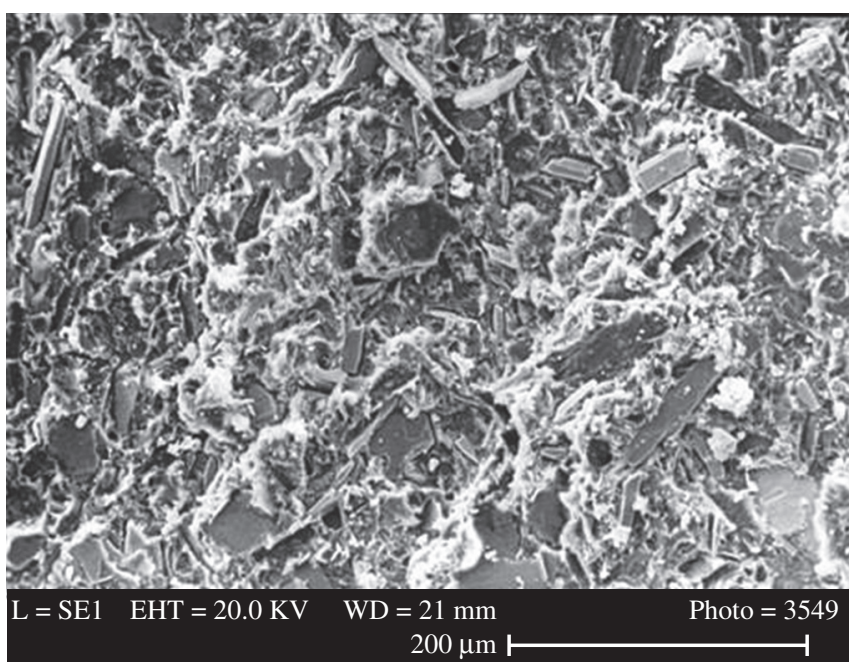

(a)

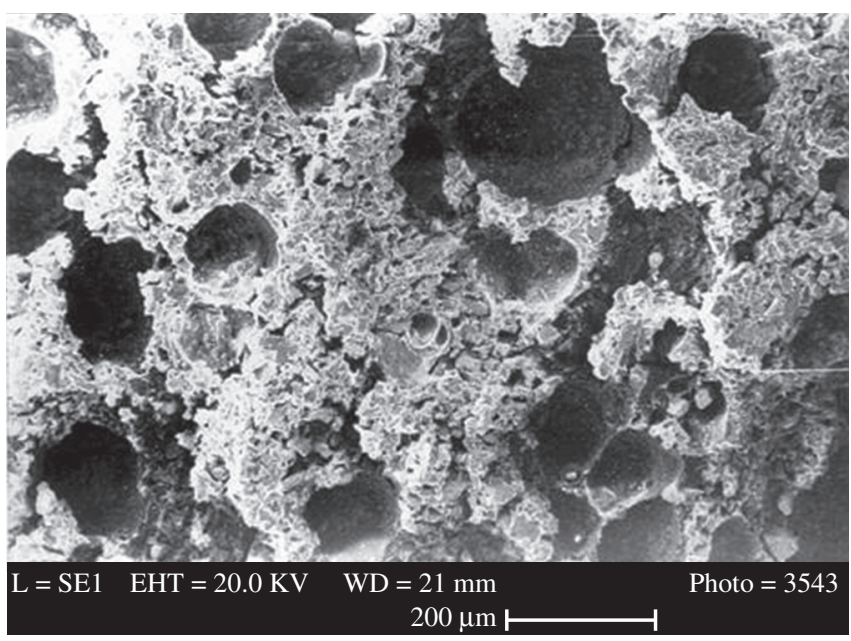

(b)

Figure 2. Secondary electron images of the fracture surface of tensile strength test specimens showing a) adhesive failure in EGS steel bonded with adhesive E1 and b) cohesive failure in EGS steel bonded with adhesive A1.

Table 3. Results of the peeling and tensile strength tests.

\begin{tabular}{|c|c|c|c|c|c|c|}
\hline \multirow[t]{2}{*}{ Adhesive } & \multirow[t]{2}{*}{ Adherent } & \multirow[t]{2}{*}{ Cleaning ${ }^{\mathrm{a}}$} & \multicolumn{2}{|c|}{ Peeling tests } & \multicolumn{2}{|c|}{ Tensile strength tests } \\
\hline & & & Strength (N/mm) & Failure type $^{\mathrm{b}}(\%)$ & Strength $(\mathrm{MPa})$ & Failure type ${ }^{\mathrm{b}}(\%)$ \\
\hline E1 & $\mathrm{BS}$ & DS & 433.8 & $100 \mathrm{C}$ & 15.1 & $70 \mathrm{C}-30 \mathrm{~A}$ \\
\hline $\mathrm{E} 2$ & $\mathrm{BS}$ & DS & 265.1 & $100 \mathrm{C}$ & 13.6 & $60 \mathrm{C}-40 \mathrm{~A}$ \\
\hline A1 & BS & DS & 241.0 & $100 \mathrm{C}$ & 02.1 & 90C-10A \\
\hline $\mathrm{E} 1$ & $\mathrm{BS}$ & $\mathrm{DS}+\mathrm{DP}$ & 409.7 & $100 \mathrm{C}$ & 16.3 & $100 \mathrm{C}$ \\
\hline $\mathrm{E} 2$ & $\mathrm{BS}$ & $\mathrm{DS}+\mathrm{DP}$ & 241.0 & $100 \mathrm{C}$ & 11.2 & $80 \mathrm{C}-20 \mathrm{~A}$ \\
\hline A1 & $\mathrm{BS}$ & $\mathrm{DS}+\mathrm{DP}$ & 265.1 & $100 \mathrm{C}$ & 01.7 & $90 \mathrm{C}-10 \mathrm{~A}$ \\
\hline $\mathrm{E} 1$ & EGS & DS & 386.6 & $100 \mathrm{C}$ & 15.1 & $100 \mathrm{~A}$ \\
\hline $\mathrm{E} 2$ & EGS & DS & 241.0 & $100 \mathrm{C}$ & 14.2 & $80 \mathrm{C}-20 \mathrm{~A}$ \\
\hline A1 & EGS & DS & 216.9 & $85 C-15 A$ & 02.0 & $95 \mathrm{C}-05 \mathrm{~A}$ \\
\hline
\end{tabular}

${ }^{a}$ Cleaning: DS = degreased with tetrachloroethylene, $\mathrm{DP}=$ pickled with $\mathrm{HCl} 15 \%$; and ${ }^{\mathrm{b}}$ Failure type: $\mathrm{A}=$ adhesive, $\mathrm{C}=$ cohesive. 


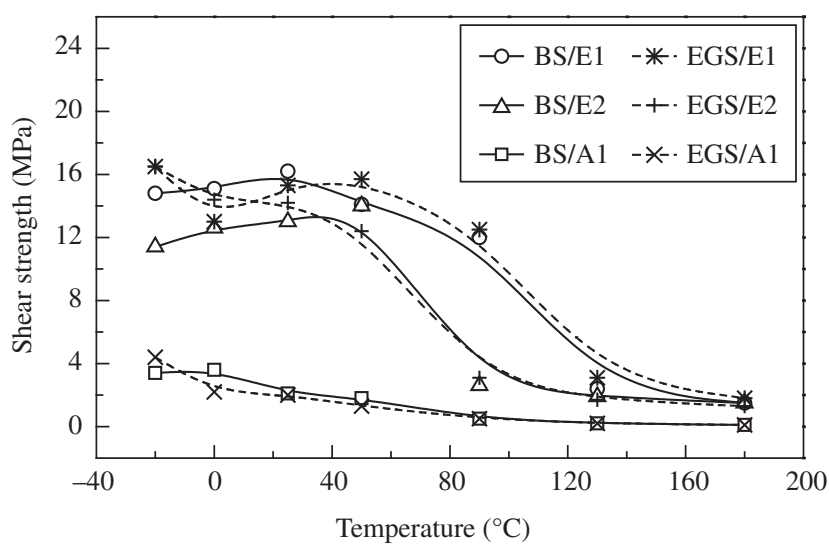

Figure 3. Effect of test temperature on the shear strength.

ated with the decreasing of the intrinsic mechanical strength of the adhesives as the temperature rises.

The results of average mechanical strength presented in Figure 4 show that heat treating the joints between 50 and $180{ }^{\circ} \mathrm{C}$ did not change their mechanical strength measured after cooling to room temperature. It is also shown in Figure 4 that the mechanical strength of the epoxy adhesives used with the BS adherent slightly increased between 50 and $100{ }^{\circ} \mathrm{C}$. This effect was not observed in the joints of the EGS adherents. Although it could be attributed to further cure of the adhesives, according to the literature ${ }^{1}$, this increase in the mechanical strength of the epoxy adhesives is associated with humidity diffusion through the adhesive/adherent interfaces, due to the presence of porous iron oxides, which were not totally removed during cleaning, or may have formed after the application of the adhesives to the BS surface. This process can lead to adhesive drying, thus increasing its strength.

\subsection{Humidity degradation of mechanical strength}

The exposure of the joints to $40{ }^{\circ} \mathrm{C}$ and $90 \%$ relative humidity caused reduction of their shear strength, as shown in Figure 5. This weakening of the joints can be associated with adhesive embrittlement and/or the formation of oxides on the adherents' surface ${ }^{9,12}$. Both phenomena are caused by the penetration of humidity into the joints, associated with the severe atmospheric conditions simulated in the tests. According to the literature ${ }^{1,7}$, humidity can diffuse into the joints by capillarity, through microcracks formed in the adhesives or through microgaps present in the adhesive/adherent interfaces.

The joints of both steels with adhesive E1 showed a compact structure, without porosity and with little oxidation on the adherents' surface. On the other hand, in all joints, the A1 adhesive always presented a porous structure. However, in spite of that, both EGS and BS joints with adhesive A1 showed high resistance to humidity degradation, which can be considered as an intrinsic property of the adhesive itself.

The E2 adhesive also showed some porosity and suffered surface oxidation, especially when joining the EGS steel. In fact, the EGS joints with adhesive E2 exhibited accentuated humidity degradation and the largest and fastest loss of mechanical strength, in relation to the other adhesives. This result can be associated with the type of oxides formed at the interface. Nakazawa ${ }^{10}$ studied the embrittlement of epoxy adhesives in zinc coated steel joints and found that the fast decrease in mechanical strength was related to formation of zinc oxides on the adhesive/adherent interfaces. He also observed that the use of phosphatized or chromatizated zinc coated steels increased the

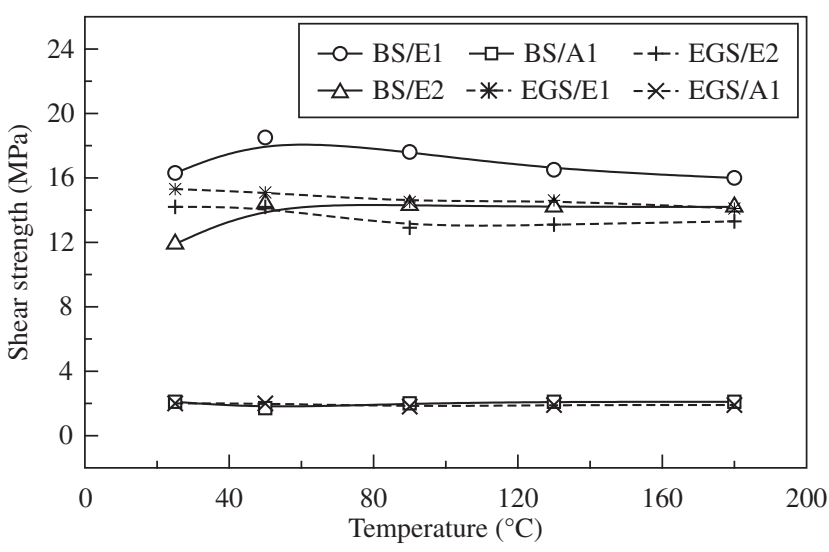

Figure 4. Effect of heat treating temperature on the shear strength.

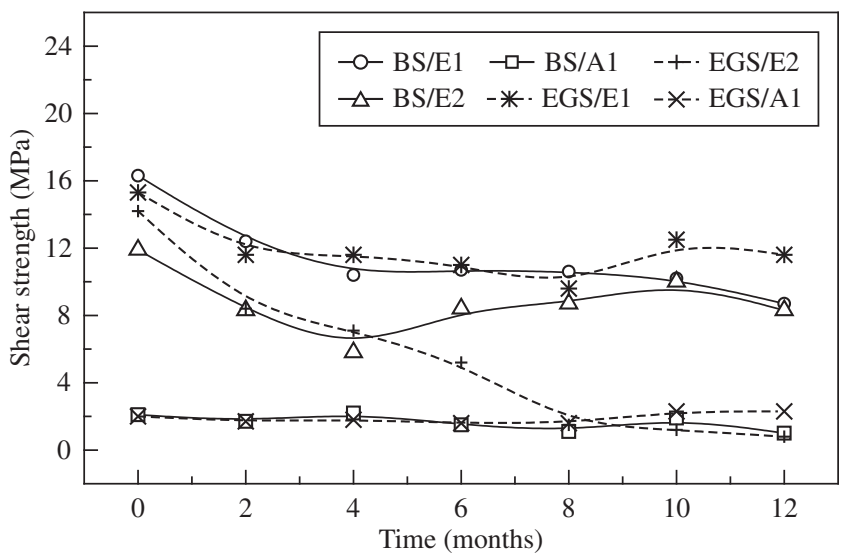

Figure 5. Effect of time of exposure at $40{ }^{\circ} \mathrm{C}$ and $90 \%$ relative humidity on the shear strength.

protection against zinc corrosion and attenuated adhesion degradation. The behavior of the epoxy adhesive joints of the uncoated BS steel found in the present work, characterized by a smaller humidity degradation than that of the EGS adherent (Figure 5), thus indicates that the bonding forces between the epoxy adhesives and iron oxides possibly formed on the BS adherents' surface are higher than those established with the zinc oxides formed on the surface of the EGS steel.

\section{Conclusions}

The mechanical strength of acrylic and epoxy joints was not influenced by the type of metallic adherent, (uncoated or zinc coated steel) nor by the cleaning procedures applied to the adherents' surface (degreasing or decreasing followed by chemical pickling). For each adherent type, the mechanical strength of the epoxy adhesive joints showed superior values as compared to acrylic adhesive joints. The shear strength of the joints was continuously reduced as the test temperature increased up to $180{ }^{\circ} \mathrm{C}$. The joints with the E1 epoxy adhesive conserved high values of mechanical strength at temperatures up to $90^{\circ} \mathrm{C}$. The other two adhesives exhibited accentuated loss of strength at lower temperatures. Heat treating the joints at different temperatures below the cure temperature produced the recovery of their mechanical strength.

After one year exposure under severe humidity conditions ( $40{ }^{\circ} \mathrm{C}$ and $90 \%$ relative humidity), the epoxy adhesives exhibited 
a strong decrease in shear strength, associated with humidity diffusion, which produced degradation of the adhesives and weakening of the bonding between adhesive and adherent. The zinc coated steel joints with the E2 epoxy adhesive showed the highest reduction in mechanical strength, associated with the weaker bond established between zinc oxides probably formed at the adherents' surface and the $\mathrm{E} 2$ adhesive.

\section{References}

1. Kinloch AJ. Durability of Structural Adhesives. New York: Elsevier Applied Science; 1986.

2. Engineered Materials Handbook. Adhesives and Sealants. vol. 3. Materials Park: ASM International, 9639 Kinsman Road Materials Park, OH 44073-0002 USA; 1990

3. Cotter JL, Hockney MGD. Metal joining with adhesives. International Metallurgical Reviews. 1974; September 19:27-31.

4. Jensen MK, Love BJ, Grant JW, Cotton J, Keiser JR, Wilson DF. Comparison study of dicyandiamide-cured epoxy bonded steel joints and polyamidoamine-cured epoxy bonded steel joints. International Journal of Adhesion and Adhesives. 2000; 20(6):437-444.
5. Pasternak H, Schwarzlos A, Schimmack N. The application of adhesives to connect steel members. Journal of Constructional Steel Research. 2004; 60(3-5):649-658

6. Hayashi K. Adhesive bonding for automobiles. Techno Japan. 1991; 24(10):27-31.

7. McNamara DK, Ahearn JS. Adhesive bonding of steels for structural applications. International Materials Reviews. 1987; 32(6):292-306.

8. Schijve J. Fatigue of Structures and Materials. Dordrecht: Kluwer Academic Publishers; 2001.

9. Harris AF, Beevers A. Effect of grit-blasting on surface properties for adhesion. International Journal of Adhesion and Adhesives. 1999; 19(6):445-452.

10. Nakazawa M. Mechanism of adhesion of epoxy resin to steel surface. Nippon Steel Technical Reports. 1994; 63:16-22, October.

11. Malucelli G, Priola A, Ferrero F, Quaglia A, Frigione M, Carfagna C. Polyurethane resin-based adhesives: curing reaction and properties of cured systems. International Journal of Adhesion and Adhesives. 2005; 25(1):87-91.

12. Sargent JP. Durability studies for aerospace applications using peel and wedge tests. International Journal of Adhesion and Adhesives. 2005; 25(3):247-256. 
